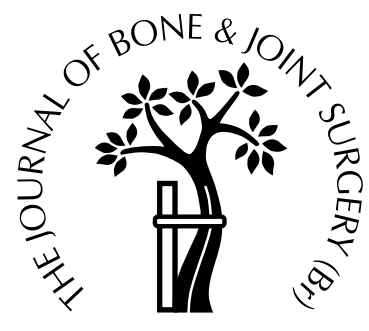

\title{
The knee-spine syndrome
}

\author{
ASSOCIATION BETWEEN LUMBAR LORDOSIS AND EXTENSION OF \\ THE KNEE
}

\author{
Yasuaki Murata, Kazuhisa Takahashi, Masatsune Yamagata, Eiji Hanaoka, \\ Hideshige Moriya \\ From Chiba University, Japan
}

D egenerative changes of the knee often cause loss of extension. This may affect aspects of posture such as lumbar lordosis. A total of $\mathbf{3 6 6}$ patients underwent radiological examination of the lumbar spine in a standing position. The knee and body angles were measured by physical examination using a goniometer. Limitation of extension of the knee was significantly greater in patients whose lumbar lordosis was $30^{\circ}$ or less. Lumbar lordosis was significantly reduced in patients whose limitation of extension of the knee was more than $5^{\circ}$. It decreased over the age of 70 years, and the limitation of extension of the knee increased over the age of 60 years. Our study indicates that symptoms from the lumbar spine may be caused by degenerative changes in the knee. This may be called the 'knee-spine syndrome'.

J Bone Joint Surg [Br] 2003;85-B:95-9.

Received 25 March 2002; Accepted after revision 11 June 2002

The radiological sagittal alignment of the lumbar spine has been described in patients with mechanical low back pain, degenerative disease of the lumbar discs, trauma, spondylolisthesis, scoliosis and postsurgical conditions, and control data have been obtained from volunteers in the USA and Greece. ${ }^{1-9}$ There have been many descriptions of this alignment based on measurements of lumbar lordosis and of sacral inclination, ${ }^{1-15}$ which is said to correlate with lumbar lordosis. ${ }^{8}$ A decrease in lumbar lordosis is associated with vertical alignment of the sacrum and when lumbar lordosis increases, the sacral inclination becomes more obtuse. Jack-

Y. Murata, $\mathrm{MD}, \mathrm{PhD}$

K. Takahashi, $\mathrm{MD}, \mathrm{PhD}$

M. Yamagata, MD, PhD

E. Hanaoka, $\mathrm{MD}, \mathrm{PhD}$

$\mathrm{H}$. Moriya, $\mathrm{MD}, \mathrm{PhD}$

Department of Orthopaedic Surgery, School of Medicine, Chiba University, 1-81 Inohana, Chuo-ku, Chiba City, Chiba 260-8677, Japan.

Correspondence should be sent to Dr Y. Murata.

(C)2003 British Editorial Society of Bone and Joint Surgery doi:10.1302/0301-620X.85B1.13389\$2.00

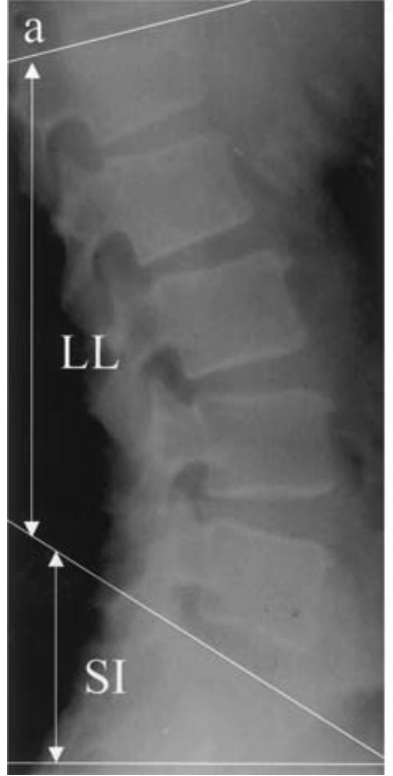

Fig. 1a

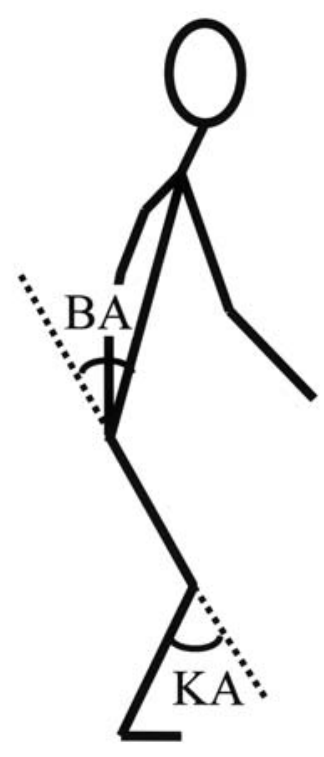

Fig. 1b
Measurements of parameters of the lumbar spine. Fig.1a - Radiograph showing the measurement of the lumbar lordotic angle (LL), which is the angle between the superior endplate of L1 and the sacral inclination (SI). The latter is the angle between the superior endplate of S1 and the horizontal line. Fig. 1b-Diagram showing measurement of the knee angle (KA) using two lines between the greater trochanter and the lateral condyle of the knee and between the lateral condyle of the knee and the lateral condyle of the ankle. The body angle (BA) was measured using two lines between the acromion and the greater trochanter, and between the greater trochanter and the lateral condyle of the knee.

son and McManus, ${ }^{1}$ who examined the relationship between these measurements and posture, found that lumbar lordosis and sacral inclination were also related to the degree of extension of the hip. This relationship has been described as the 'hip-spine syndrome'. ${ }^{16}$ If a patient develops a fixed flexion deformity of the hip, there may be an associated loss of lumbar lordosis. Altered lumbar lordosis may cause disc degeneration and radicular pain.

Many patients also have degenerative changes of the knee with loss of extension which may affect posture and lumbar lordosis. Our aim was to investigate the relationship between lumbar lordosis and extension of the knee and to relate low back pain to symptoms in the knee. 


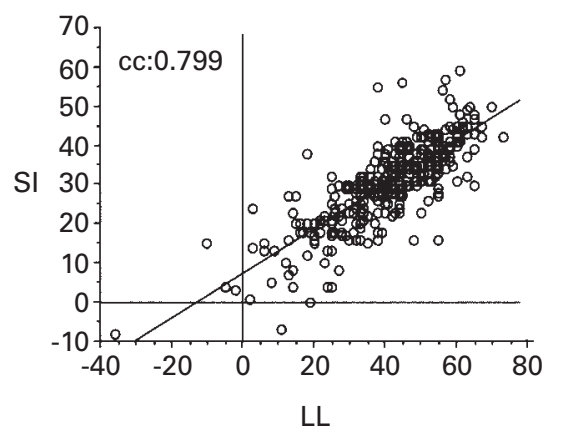

Fig. 2a

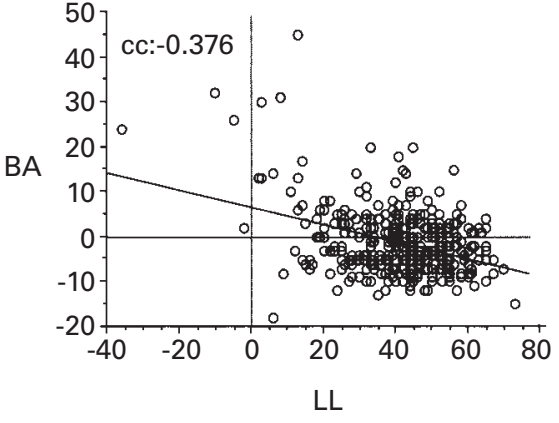

Fig. $2 b$

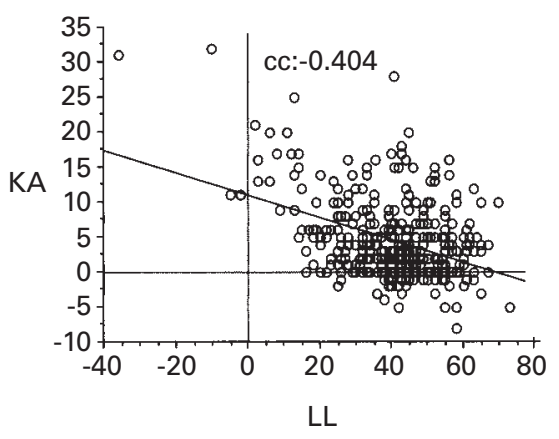

Fig. 2c

Graphs showing a) a correlation between lumbar lordosis (LL) and sacral inclination (SI), b) no correlation between LL and body angle (BA) and c) a correlation between LL and the angle of the knee (KA).

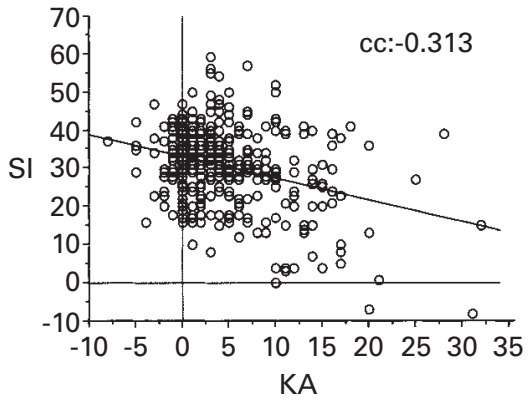

Fig. 3a

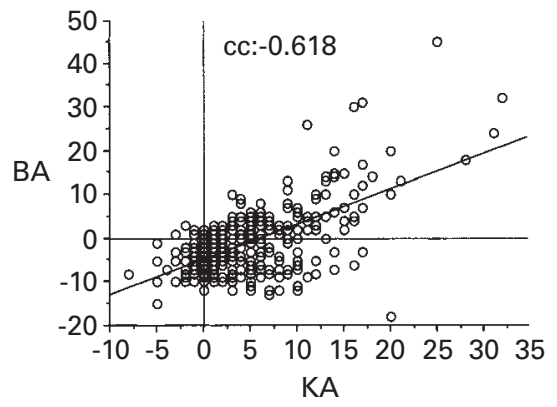

Graphs showing a) no correlation between KA and sacral inclination (SI) and b) a correlation between $\mathrm{KA}$ and BA.

\section{Patients and Methods}

We studied 365 patients (150 men and 216 women) with pain in the knee and/or low back pain. They underwent radiological examination of the lumbar spine in a standing position. Those with previous spinal surgery and/or fractures were excluded. We also excluded those with a functional discrepancy of limb length and those with scoliosis including a degenerative lumbar scoliosis, whose curvature was more than $10^{\circ}$. During measurement, the patients were asked to extend the knee to its maximum, to position the hips perpendicular to the film, and to grip a supporting bar with extended arms. The x-ray cassette was set up to be parallel to the floor. Measurements were made on each lateral radiograph by two independent observers (YM, EH), using Cobb's method. ${ }^{17}$ The angle between the superior endplates of L1 and S1 was used as the lumbar lordotic angle, while the angle between the superior endplate of S1 and the horizontal was used as the sacral inclination (Fig. 1a). The angle of the knee and the body angle were measured as shown in Figure $1 \mathrm{~b}$. The four points for the angles of the knee and the body angle were determined by physical examination using a goniometer.

Of the 366 patients, 107 had pain in the knee and 348 low back pain. The duration of the lumbar symptoms was recorded. When considering degenerative changes, data from patients who were less than 50 years of age were thereafter excluded from further analysis. The patients were classified into four groups: group A) 51 patients with lumbar lordosis of over $50^{\circ}$; group B) 56 patients with lordosis of $41^{\circ}$ to $50^{\circ}$; group C) 45 patients with lordosis of $31^{\circ}$ to $40^{\circ}$; and group D) 64 patients with lordosis of $30^{\circ}$ or less (Fig 5).

Statistical analysis was undertaken using Student's $t$-test. All probability values were calculated within a confidence interval of $95 \%$.

\section{Results}

With regard to lumbar lordosis and sacral inclination, intraobserver variance ranged from 0.0 to 5.0 with a mean of $1.8(95 \%$ confidence limit $(\mathrm{CI}) \pm 1.4)$ and interobserver variance from 0.0 to 10.0 with a mean of 2.7 (95\% CI \pm 2.2). With regard to knee and body angles, intraobserver variance ranged from 0.0 to 5.0 with a mean of 2.1 (95\% CI \pm 1.9 ) and interobserver variance ranged from 0.0 to 8.0 with a mean of $2.5(95 \% \mathrm{CI} \pm 2.3)$.

Lumbar lordosis showed a correlation with sacral inclination (Fig. 2a) and knee angle (Fig. 2c), although there was no correlation with body angle (Fig. 2b). Knee angle, however, correlated with body angle (Fig. 3b) although there was no correlation with sacral inclination (Fig. 3a). 

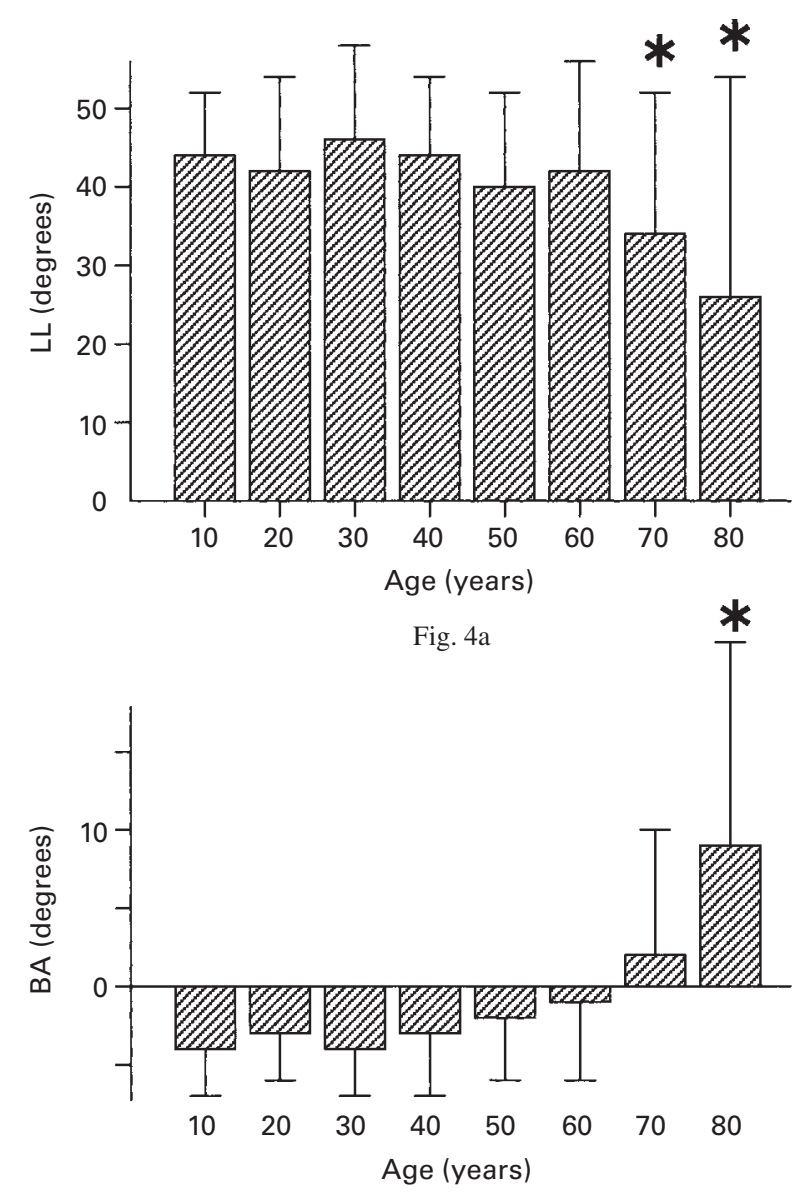

Fig. 4c

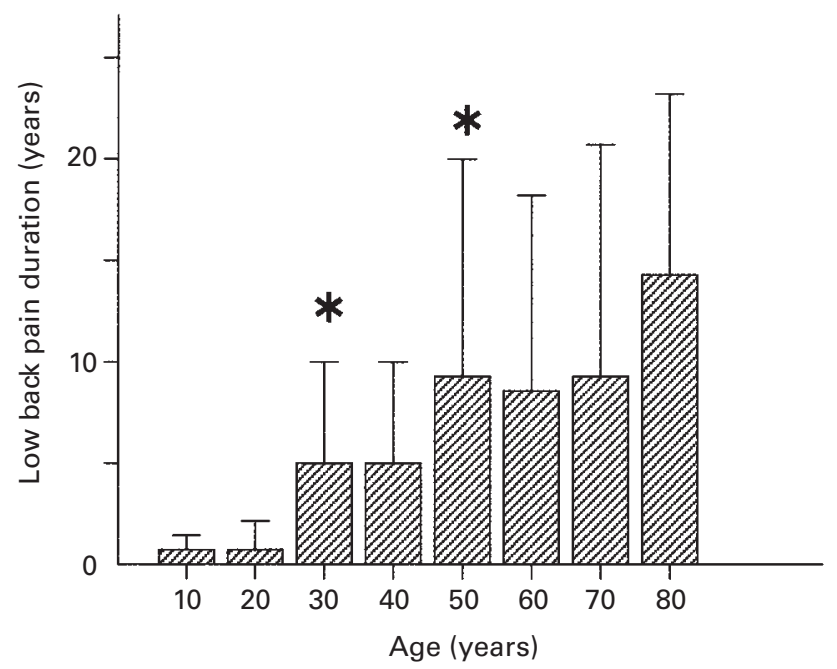

Fig. $4 \mathrm{e}$

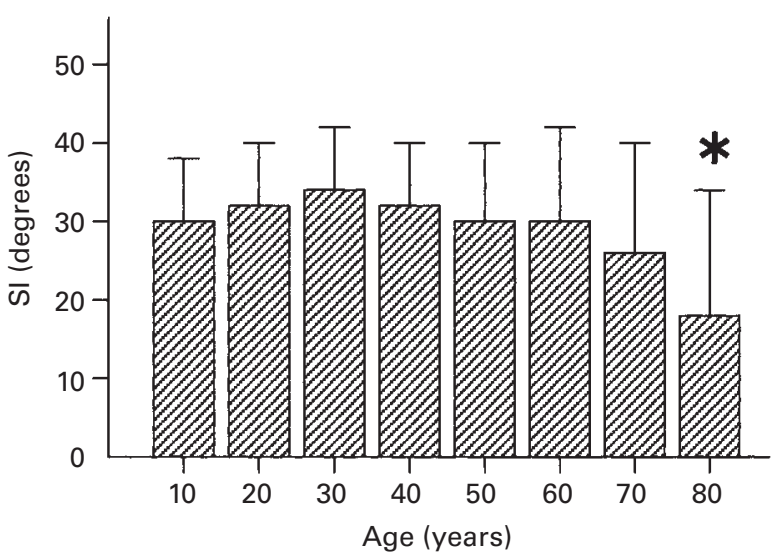

Fig. $4 b$

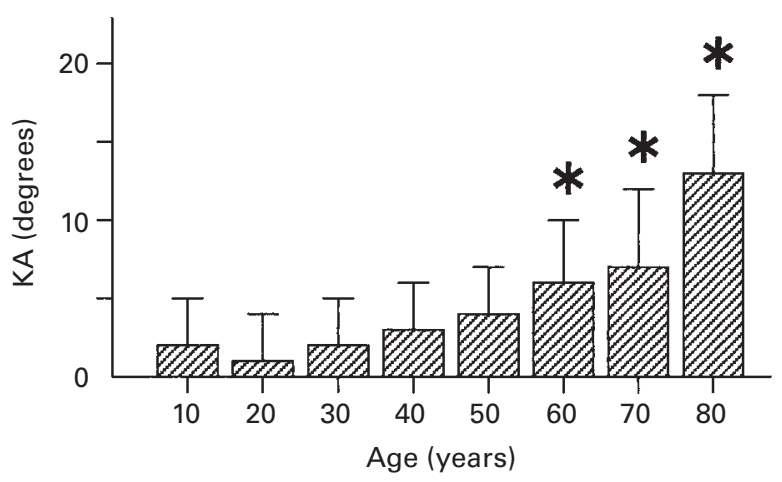

Fig. 4d

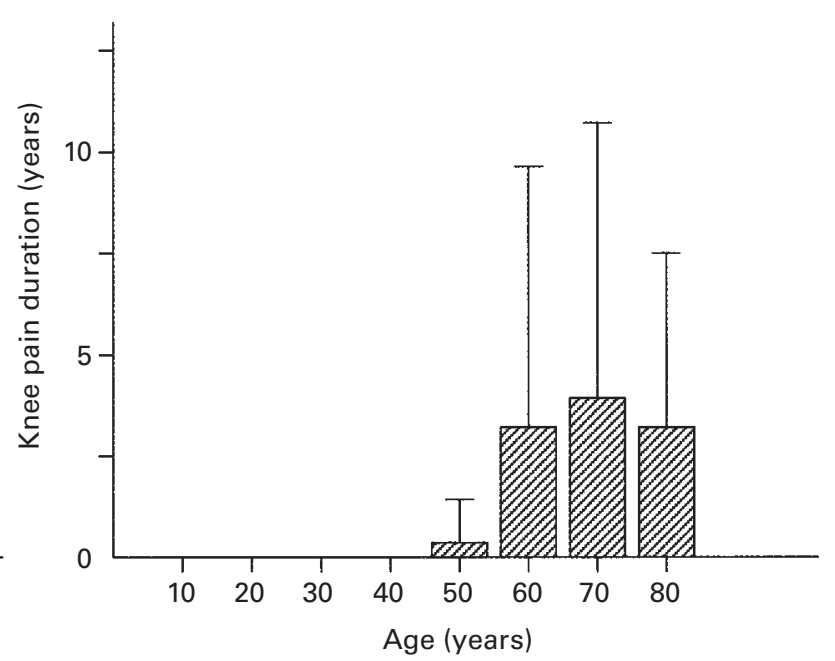

Fig. 4f

Histograms showing the distribution according to age for a) the mean lumbar lordotic angle (LL), b) the mean sacral inclination (SI), c) the mean body angle (BA), d) the mean knee angle (KA), e) the mean duration of low back pain (LBP), and f) the mean duration of knee pain (KP). 


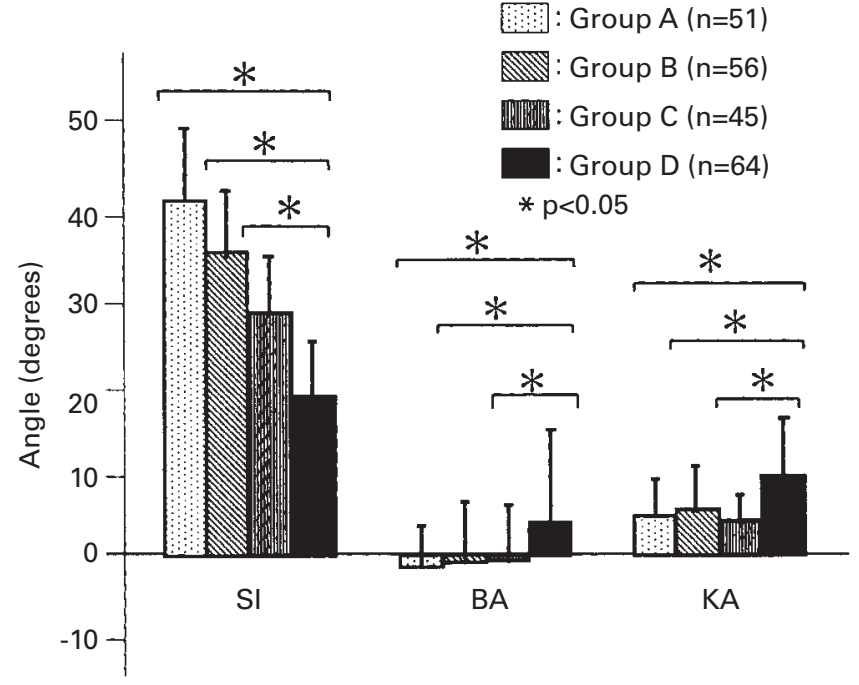

Fig. 5a

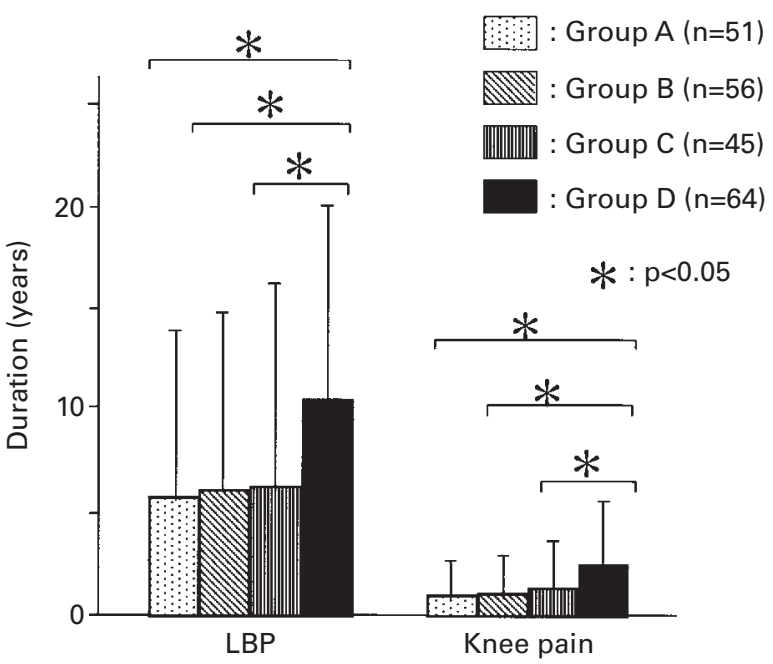

Fig. 5b

Histogram showing a) the mean values for each measurement among patients who were aged 50 years or older and b) the duration of low back pain (LBP) and knee pain.

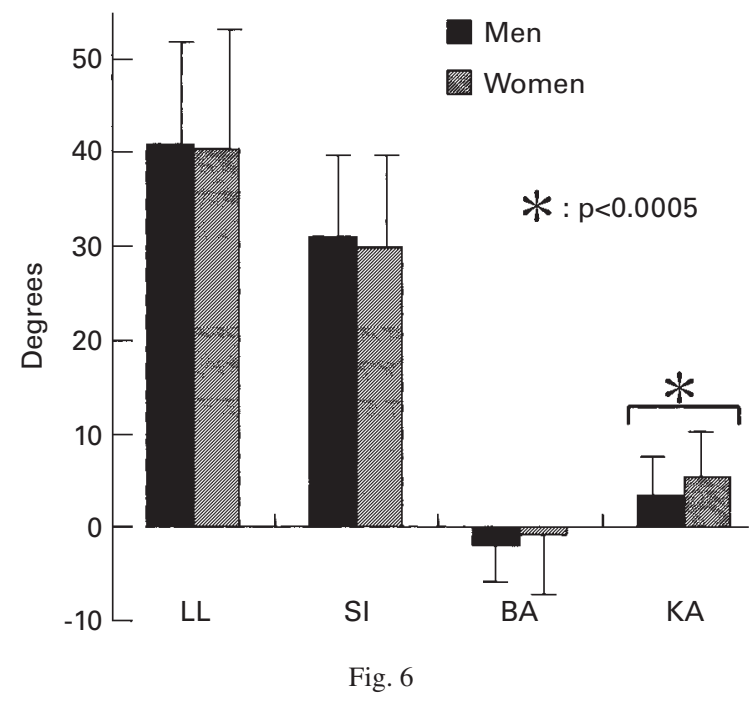

Histogram showing the distribution according to gender for all measurements.

The distribution of the mean angles and the duration of the symptoms in each age group are shown in Figure 4. These angles were smaller among patients who were between 70 and 79 years of age and over 80 years of age with regard to lumbar lordosis (Fig. 4a), over 80 years of age with regard to sacral inclination (Fig. 4b) and body angle (Fig. 4c), and between 60 and 69 years and 70 and 79 years and over 80 years of age with regard to knee angle (Fig. 4d). As for low back pain, the mean duration of symptoms was significantly longer in patients who were in their thirties or fifties (Fig. 4e). There was no statistically significant difference with regard to the duration of pain in the knee (Fig. 4f).
The mean values for each measurement among patients aged 50 years or more are shown in Figure 5. The knee and body angles were significantly greater in group $\mathrm{D}$ than in groups A, B and C (Fig. 5a). With regard to sacral inclination, the mean value was significantly greater in group $\mathrm{D}$ than in group $\mathrm{C}$, in group $\mathrm{C}$ than in group $\mathrm{B}$ and in group $\mathrm{B}$ than in group A (Fig. 5a). The duration of both knee and low back pain was also significantly longer in group $\mathrm{D}$ than in groups A, B and C (Fig. 5b).

The mean values for each measurement according to gender are shown in Figure 6. There was no significant difference between men and women with regard to lordotic angle, sacral inclination and body angle, although the knee angle in women was significantly greater than in men.

\section{Discussion}

It has been suggested that loss of lordosis is associated with low back pain. $1,3,4,12,14,15$ Some authors have indicated that a posture with a reduced lordosis is associated with an increased intradiscal pressure which may cause low back pain. ${ }^{4,10}$ In a study from Greece, a decrease in lumbar lordosis was reported in an asymptomatic population aged more than 60 years $^{9}$ and a similar study in the USA reported a decrease in lumbar lordosis above the age of 40 years. $^{7}$ These results suggest that degenerative changes in lumbar alignment may initially cause a loss of lordosis. These studies have used lateral radiographs of subjects in a fixed or static posture. The posture of the patients in our study was obtained with full extension of the knee and with the arms extended. There have been no studies during walking and further analysis of the static 
and dynamic sagittal balance of the spine and knee is required.

Degenerative changes of the knee often cause limitation of extension. In our study, limitation of extension of the knee was significantly greater in patients whose lumbar lordosis was $30^{\circ}$ or less (Fig. 5) and the duration of pain in the knee was significantly longer. There was a correlation between the knee angle and lumbar lordosis (correlation coefficient; -0.404, Fig. 2c), indicating that the loss of lordosis is related to degenerative changes in the knee.

It is difficult to determine whether the deformity of the lumbar spine or the knee is the primary factor. We found a decrease in lumbar lordosis above the age of 70 years and loss of extension above the age of 60 years (Fig. 4). This suggests that degenerative changes in the knee may be a factor in the development of similar changes in the lumbar spine with loss of lordosis. This may be called the 'knee-spine syndrome'.

No benefits in any form have been received or will be received from a commercial party related directly or indirectly to the subject of this article.

\section{References}

1. Jackson RP, McManus AC. Radiographic analysis of sagittal plan alignment and balance in standing volunteers and patients with low back pain matched for age, sex and size: a prospective controlled clinical study. Spine 1994;19:1611-18.

2. Wood KB, Kos P, Schendel M, Persson K. Effect of position on the sagittal-lane profile of the thoracolumbar spine. J Spinal Disord 1996;9:165-9.

3. Jackson RP, Peterson MD, McManus AC, Hales C. Compensatory spinopelvic balance over the hip axis and better reliability in measuring lordosis to the pelvic radius on standing lateral radiographs of adult volunteers and patients. Spine 1998;23:1750-67.
4. Lord MJ, Small JM, Dinsay JM, Watkins RG. Lumbar lordosis: effects of sitting and standing. Spine 1997;22:2571-4.

5. Chernukha KV, Daffner RH, Reigel DH. Lumbar lordosis measurement: a new method versus Cobb technique. Spine 1998;23:74-9.

6. Hasday CA, Passoff TL, Perry J. Gait abnormalities arising from latrogenic loss of lumbar lordosis secondary to Harrington instrumentation in lumbar fractures. Spine 1983;8:501-11.

7. Gelb DE, Lenke LG, Bridwell KH, Blanke K, McEnery KW. An analysis of sagittal spinal alignment in 100 asymptomatic middle and older aged volunteers. Spine 1995;20:1351-8.

8. Vedantam R, Lenke LG, Keeney JA, Bridwell KH. Comparison of standing sagittal spinal alignment in asymptomatic adolescents and adults. Spine 1998;23:211-5.

9. Korovessis PG, Stamatakis M, Baikousis A. Reciprocal angulation of vertebral bodies in the sagittal plane in an asymptomatic Greek population. Spine 1998;23:700-4.

10. Adams MA, Hutton WC. The effect of posture on the lumbar spine. $J$ Bone Joint Surg [Br] 1985;67-B:625-9.

11. Bernhardt M, Bridwell KH. Segmental analysis of the sagittal plane alignment of the normal thoracolumbar junction. Spine 1989;14:71721.

12. Itoi E. Roentgenographic analysis of posture in spinal osteoporotics. Spine 1991;16:750-6.

13. Stagnara P, Mauroy JC, Dran G, et al. Reciprocal angulation of vertebral bodies in a sagittal plane: approach to references for the evaluation of kyphosis and lordosis. Spine 1982;7:335-42.

14. Troyanovich SJ, Cailliet R, Janik TJ, Harrison DD, Harrison DE. Radiographic mensuration characteristics of the sagittal lumbar spine from a normal population with a method to synthesize prior studies of lordosis. J Spinal Disord 1997;10:380-6.

15. Williams MM, Hawley JA, McKenzie RA, Wijmen PM. A comparison of the effects of two sitting postures on back and referred pain. Spine 1991;16:1185-91.

16. Offierski CM, Macnab I. Hip-spine syndrome. Spine 1983;8:316-21.

17. Cobb JR. Outline for the study of scoliosis. In: Edwards JW, ed. Instructional course Lectures. Vol 5. Ann Arbor: American Academy of Orthopaedic Surgeons, 1948. 